\title{
Low Dose Rabbit Anti-Thymocyte Globulin as an Induction immunosuppression in High-Risk Renal Transplant Recipients
}

\begin{abstract}
High immunologic risk recipients pose a major challenge in transplantation. It is associated with early acute rejection post-transplantation and leads to decrease patient and graft survival. The need for effective immunosuppression early post-transplantation has resulted in emerging of induction protocols. Biologic agents used for induction are classified to monoclonal and polyclonal which are either depletive or non-depletive antibody therapies. Choosing the best agent and optimal dose remains a controversial issue and depends on many factors including the proper assessment of the immunologic risk, efficacy and safety of the used agent. There is no consensus for the optimal agent used as induction immunosuppression in kidney transplantation. rATG use is associated with decreased incidence of delayed graft function and acute rejection episodes.
\end{abstract}

Keywords: kidney transplantation, induction immunosuppression, immunologic risk, antibody therapy, rejection, ratg
Volume 4 Issue 4 - 2017

\author{
Tariq Zayan, ${ }^{1,2}$ Ahmed Aref, ${ }^{1,2}$ Ajay Sharma, ${ }^{2,3}$ \\ Ahmed Halawa 2,4 \\ 'Department of Nephrology, Sur hospital, Oman \\ ${ }^{2}$ Faculty of Health and Science, Institute of Learning and \\ Teaching, University of Liverpool, UK \\ ${ }^{3}$ Royal Liverpool University Hospital, Liverpool, UK \\ ${ }^{4}$ Sheffield Teaching Hospitals, Sheffield, UK
}

\begin{abstract}
Correspondence: Ahmed Halawa, Consultant Transplant Surgeon, Sheffield Teaching Hospital, University of SheffieldUniversity of Liverpool, UK, Tel 00447787542 I 28, Fax 0044|I427| 4604, Email ahmed.halawa@sth.nhs.uk
\end{abstract}

Received: October 29, 2016 | Published: April 5, 2017

\section{Introduction}

The number of high-risk patients coming for renal transplantation is a growing. Modern immunosuppression minimises the rate of acute rejection dramatically; however, it is not mandatory to improve patient and long-term allograft outcomes concurrently. ${ }^{1}$ Defining patients as 'high risk for renal transplantation' is essential to improve transplant pharmacotherapy and depends on understanding variables of the recipient, donor and allograft. ${ }^{2}$ There are several important reasons why induction therapy is utilised. First, the induction agents are highly immunosuppressive, allowing for a significant reduction in acute rejection rates and improved 1-year graft survival. ${ }^{3}$ Second, due to their unique pharmacologic effect, these agents are often considered essential for use in patients at high risk of poor short-term outcomes. ${ }^{4}$
The improvements in short-term outcomes gained from the use of induction therapies cannot be denied. Despite these advances, studies detailing the impact of induction therapy on long-term allograft function or survival are lacking. On the other hand, when using these potent immunosuppressive agents, the host defences are often profoundly impaired, which increases the risk of opportunistic infections and malignancy as we indicated in our earlier publication (Table 1). ${ }^{2,5}$ The definition of high-risk renal transplantation is now extended to include factors such as donor and recipient age, donor cause of death, time to transplant, as well as several other pre- and post-procurement variables that influence graft survival. Induction with biologic agents is used in renal allograft recipients for two reasons (Table 2):

Table I Induction immunosuppressive strategies in renal transplantation ${ }^{85}$

\section{Conventional Drugs Induction}

Antibody Induction

Drugs used in the Protocol Initial high doses of $\mathrm{CNI}+$ antimetabolite + steroids.

Indications

Advantages

Disadvantages
Low immunological risk transplantation

- Cheap.

- Less risk of infection.

- Easier to monitor.

- Not suitable in high risk cases.

- Higher doses of drugs mean more adverse effects (e.g. DGF with CNI).
Depleting or non-depleting biological antibodies + lower doses of conventional drugs.

High immunological risk transplantation.

- Potent and effective immune-suppression.

- Allow lower doses of maintenance immunosuppression (and even avoidance of some of them)

- Expensive.

- Higher risk of infection.

- Complex prescription and monitoring. 
Table 2 Uses of biologic agents in kidney transplantation

\begin{tabular}{|c|}
\hline Induction \\
Rejection prophylaxis \\
Minimization protocol \\
\hline ABO incompatible transplantation \\
Desensitization protocols \\
\hline Rejection Treatment \\
\hline Prophylaxis/treatment of recurrent primary disease \\
\hline
\end{tabular}

(1) To augment the effect of initial immunosuppression in patients with high immunological risk poor matching of human leukocyte antigen (HLA), sensitised, marginal donor transplant or retransplantation or (2) To improve minimization protocol aimed at decrease the use of steroids or calcineurin inhibitors (CNI), or both (2).

\section{Definition of sensitization}

Sensitization is defined as the presence of preformed alloantibodies in the serum of a prospective transplant recipient. In other words, it is pretransplant humoral all immunization. These alloantibodies are usually anti-HLA class I antibodies but may also include antiHLA class II or non-HLA antibodies. ${ }^{6}$ They formed in response to prior exposure to foreign antigens. ${ }^{7}$ Of note, in addition to this humoral sensitization, there also appears to be donor-reactive $\mathrm{T}$ cell sensitization "cellular sensitization", which measured with a delayed type hypersensitivity assay. ${ }^{8}$ To what degree this phenomenon may be present pretransplant and manifest post-transplant is not clear.

\section{The importance of sensitization}

United Network for Organ Sharing (UNOS) data indicated that approximately $20 \%$ of patients on the transplant waiting list have a panel reactive antibody (PRA) of greater than $20 \%$ and in France, more than $50 \%$ of patients have reactive PRAs. ${ }^{9}$ Hyper acute rejection (HAR) with immediate and universal graft loss historically was a common occurrence in these patients. This problem has been largely eliminated using sensitive cross match techniques. Still, sensitised patients wait longer for compatible allograft and are at increased risk for early acute humoral rejection and have worse short-term and longterm outcomes. ${ }^{10-12}$

The presence of anti-HLA antibodies post-transplantation is associated with acute and chronic rejection as well as decreased graft survival in various organs transplanted, including kidneys. ${ }^{13}$ Renal transplant patients with post-transplant HLA alloantibodies were 5-6 times more likely to develop chronic rejection. ${ }^{14,15}$ Animal and in vitro human models suggested that a repair response to donor-specific antibodies might result in arterial thickening associated with chronic rejection..$^{16}$ To what extent the patients with pretransplant sensitization may be at risk of post-transplant alloantibody-induced graft pathology is not quantifiable. It is not clear as to what extent the post-transplant humoral mediated rejection involves a de novo versus anamnestic response.

\section{Causes of sensitization}

The primary sources for sensitization of kidney transplant patients are pregnancy, blood transfusions, and prior transplants.
These situations may expose the recipients' immune system to foreign antigens, especially HLA molecules. If the immune system is not suppressed, the patient will appropriately produce antibodies against these alloantigens. These sensitising events appear to have a cumulative and interacting impact on the PRA. ${ }^{17}$ The rate of sensitization seems greater in retransplantation as compared to first transplantation. The sensitising effect of pregnancy appears to be more important in first transplants than in retransplants. The more transfusion numbers, the higher level of PRAs, and the effect seems to be modulated by sex and pregnancies. ${ }^{18}$ It has hypothesised that pregnant women may sensitise at the time of delivery with exposure to parental HLA antigens expressed by foetal cells. ${ }^{19}$

\section{Strategies to optimize outcomes in sensitized patients}

\section{Limiting alloimmunizing events}

Avoiding transfusions in patients who may eventually need kidney transplantations would lessen exposure to alloantigens. ${ }^{20}$

\section{Pre-transplantation Cross matching}

It is used primarily to prevent hyperacute rejection, an immediate and irreversible HLA class I antibody-mediated rejection of the allograft. Sophisticated techniques of crossmatching have extended their use to identifying the presence of alloantibodies that do not produce hyperacute rejection but are associated with less fulminant adverse immunologic outcomes. ${ }^{21}$

\section{Immunosuppression}

Aspects of immunosuppression of highly sensitised kidney transplant patients include desensitisation therapy prior transplantation, induction therapy with transplantation, maintenance therapy after transplantation, and rescue therapy in the event of acute humoral rejection..$^{22}$ The corresponding author uses ATG in highly sensitized patients and also in transplantation across positive crossmatch (in conjunction with plasmapheresis).

\section{Strategy for rabbit Anti-Thymocyte Globulin (rATG) dose}

The seven-day course consisted of rATG at $1.5 \mathrm{mg} / \mathrm{kg}$ intravenously intra-operatively, then daily for six days.

\section{Dose preparation and infusion}

i. $100 \mathrm{mg}$ IV hydrocortisone, $10 \mathrm{mg}$ IV chlorpheniramine and $1 \mathrm{~g}$ oral paracetamol given 60 minutes before each dose.

ii. The initial main infusion should be $1.5 \mathrm{mg} / \mathrm{kg}$ dissolved in 500 $\mathrm{ml}$ of $0.9 \%$ normal saline (maximum concentration $1 \mathrm{mg} / 2 \mathrm{ml}$ ) infused centrally over 12 hours.

iii. Measure and record vital signs every 15 minutes for the first hour, every 30 minutes for next hour and then hourly until the infusion is complete.

\section{RabbitATG in combination with maintenance therapy}

Intravenous methylprednisolone $(7 \mathrm{mg} / \mathrm{kg})$ intraoperative then daily with rapid tapering till reach oral $20 \mathrm{mg}$ prednisolone daily. Antimetabolites (such as azathioprine or mycophenolate mofetil) are 
discontinued during the rATG course and are recommenced only when total white cell count $($ WCC $)>4.0 \times 109 / \mathrm{L}$. CNIs as maintenance immunosuppression are commenced during the postoperative period when the urine output is good and the serum creatinine drops to $<3.5 \mathrm{mg} / \mathrm{dl}$. Tacrolimus, initiated at of $0.1 \mathrm{mg} / \mathrm{kg}$ orally two times per day, adjusted to achieve target trough level depending on the patient's degree of immunologic risk and the time elapsed since the transplant. If cyclosporine is used then it is initiated at $4 \mathrm{mg} / \mathrm{kg}$ orally two times per day. Doses of cyclosporine are subsequently adjusted to attain target trough level of 150 to $300 \mathrm{ng} / \mathrm{mL}$ (whole blood by immunoassay) during the first three months post-transplant and 75 to $150 \mathrm{ng} / \mathrm{mL}$ thereafter. As an alternative to measuring cyclosporine trough levels, $\mathrm{C} 2$ or peak level two hours post dose can also be used. Doses of cyclosporine are adjusted to target $\mathrm{C} 2$ levels to be 800 to $1400 \mathrm{ng} / \mathrm{mL}$ during the first three months' post-transplant and then 400 to $600 \mathrm{ng} / \mathrm{mL}$ after this period.

\section{Non-immunosuppressive components}

Both the donor and recipient should be tested for cytomegalovirus (CMV) status; valganciclovir used as primary prophylaxis therapy in patients at risk for CMV infection. Also, should administer prophylactic trimethoprim-sulfamethoxazole to prevent pneumocystis jiroveci pneumonia, sepsis, and urinary tract infection.

\section{Other induction agents}

Many agents are clinically available to target the components of alloimmunity that are amplified shortly after transplantation. Several agents have been studied in clinical trials in combination with standard maintenance regimens and shown to be efficacious, but few prospective studies have compared the prominent agents, and none of them has distinguished itself as clearly superior compared to the others. Most trials have used the surrogate endpoint of early acute rejection rather than a more definitive endpoint of patient or graft survival. Almost all trials have layered "specialised" induction agents on an installation base of bolus methylprednisolone. As with all forms of aggressive immunosuppression, induction therapy using rATGis associated with increased incidences of infectious and malignant complications. ${ }^{23}$ The risks of post-transplant lymphoproliferative disease (PTLD) and death ae higher from malignancy when combined with conventional maintenance immunosuppression. ${ }^{24,25}$ Induction therapy refers to the use of depleting rabbit anti-thymocyte globulin (r-ATG); Muromonab-CD3 (OkT3); anti-CD 52 (alemtuzumab); anti CD-20 (rituximab), or non-depleting antibodies (anti-CD 25 monoclonal antibodies/IL-2 receptor antibodies) within the first 2-6 weeks after transplantation. ${ }^{26}$

\section{Mechanism of action of ATG}

Rabbit ATG is a polyclonal lymphocyte depleting antibody that contains a wide variety of antibody specificities: immune response antigens, adhesion and cell trafficking molecules, and molecules involved in various pathways. The exact mechanism of immunosuppressive action not fully elucidated; appears to include clearance of peripheral antigen-reactive $T$ lymphocytes ( $\mathrm{T}$ cells) and modulation of T-cell activation, homing, and cytotoxicity. Although rATG has been shown to deplete a variety of immune cells, the primary mechanism of action is T-cell depletion. rATG also modulates cell surface expression of adhesion molecules and chemokine receptors, thus interfering with leukocyte-endothelial interactions that play a role in ischaemia/reperfusion injury (IRI). ${ }^{27}$ It is also has a wide range of anti-B cell actions as illustrated below in Figure 1.

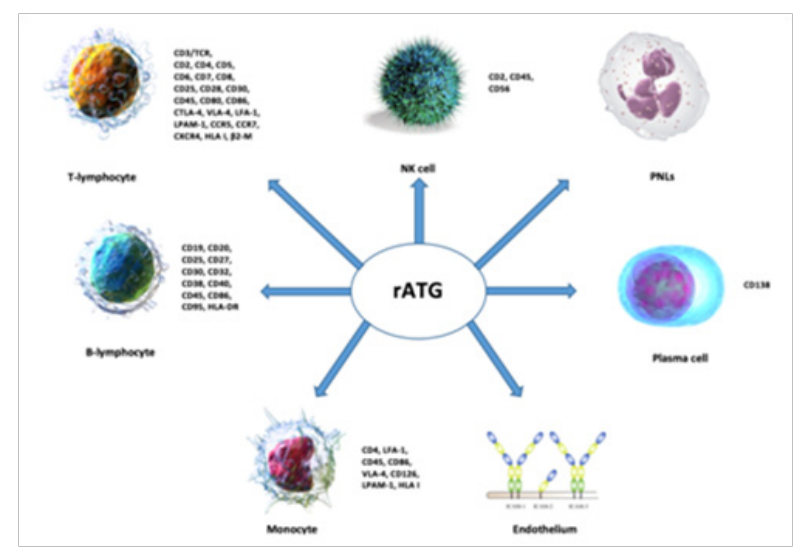

Figure I RATG mechanism of action and its cellular binding sites.

\section{Dosing}

The use of rATG as induction therapy for the high-risk renal transplant recipient is off-label. So, no universal agreement on the dose for induction. ${ }^{27}$

\section{Strategies proposed for the use of rATG based on the following}

i. Total dose of induction course

ii. Time of initial dose: pre or intraoperative

iii. Duration of induction course. ${ }^{28,29}$

\section{Strategies}

Strategy 1: Three days' induction: $3 \mathrm{mg} / \mathrm{kg}$ administered intraoperative dose before anastomosis of transplant, followed by 1.5 $\mathrm{mg} / \mathrm{kg} /$ dose for two consecutive days. ${ }^{29}$

Strategy2: Seven days' induction: $1.5 \mathrm{mg} / \mathrm{kg}$ administered intraoperative dose before anastomosis of transplant, followed by $1.5 \mathrm{mg} / \mathrm{kg} / \mathrm{dose}$ for six consecutive days. ${ }^{29}$ There was no significant difference in acute rejection rate, patient and graft survival between 3 days and 7 days induction strategy. The three days' regimen is associated with shorter hospital stay and leads to more sustained lymphocyte depletion. ${ }^{29}$

Strategy 3: Single dose induction: $5 \mathrm{mg} / \mathrm{kg}$ administered before transplantation. ${ }^{30}$

Strategy 4: Rabbit ATG total cumulative dose: $1-6 \mathrm{mg} / \mathrm{kg} / \mathrm{dose}$ for a duration ranging from one to ten days. By assessing differences between total cumulative doses in high-risk patients, there were no differences in immunosuppressive results between more or less than $7.5 \mathrm{mg} / \mathrm{kg}$. Total dose is less than $7.5 \mathrm{mg} / \mathrm{kg}$ was associated with less infection and lymphoma. ${ }^{31}$ Decreasing total cumulative dose to less than $3 \mathrm{mg} / \mathrm{kg}$ was associated with more rejection episodes. ${ }^{32}$

Strategy 5: rATG total cumulative dose $6 \mathrm{mg} / \mathrm{kg}$ divided over 3-5 days with daily dose of $1-2 \mathrm{mg} / \mathrm{kg} / \mathrm{dose}$. This regimen showed the best balance between immunosuppression and infection risk. ${ }^{32-37}$ 


\section{Strategy 6: Innovative strategies:}

i. Intermittent, based on monitoring of CD3+ cell count. ${ }^{38}$

ii. Alternate-day, until calcineurin inhibitor target level, is achieved. ${ }^{39}$

\section{Rabbit anti-thymocyte globulin induction versus no induction}

Two short-term randomised trials report that recipients who had received a kidney from deceased donor had a reduced rejection rate with $\mathrm{rATG} .{ }^{40,41} \mathrm{~A}$ parallel six-month multicentre European trial included 555 recipients who had received a kidney transplant from a deceased donor. Patients were randomised to receive a CNI (either tacrolimus or cyclosporine), steroids, azathioprine, plus rATG induction $(1.25 \mathrm{mg} / \mathrm{kg}$ for ten days), or tacrolimus, azathioprine, plus steroids, without an induction therapy ${ }^{40}$ Treated patients with rATGtacrolimus had the lowest incidence of biopsy-proven acute rejection (BPAR) (15.1\% vs. $21.2 \%$ rATG-cyclosporine and $25.4 \%$ tacrolimusno inductions; $\mathrm{P}=\mathrm{ns}$ ). However, patients and graft survival rates, as well as serum creatinine levels, were similar in both groups at six months' post-transplantation. The patients receiving rATG experienced a significantly higher incidence of leucopenia, thrombocytopenia, serum sickness, fever, and CMV infection $(\mathrm{P}<0.05) .^{40}$ Even though, these trials have demonstrated that an ATG induction therapy can delay the initiation of CNIs and lower the incidence of early rejection episodes at the expense of reversible thrombocytopenia and leucopenia, and increased infections particularly CMV. These raises the question as to whether universal anti-CMV prophylaxis in this setting is required and, if it is, will it increase the financial costs incurred during the early post-transplant period. ${ }^{41}$

\section{Rabbit anti-thymocyte globulin induction versus non-depleting agents}

A recent meta-analysis of six randomised studies that included a total 853 patients showed no differences between ATG (all preparations) or basiliximab regarding outcomes, which included BPAR, delayed graft function, graft loss, and patient death. The results were similar across the two treatment groups with regards to biopsyproven rejection (RR: $1.15,95 \% \mathrm{CI}: 0.88-1.52, \mathrm{P}=0.31$ ), delayed graft function (RR: $1.02,95 \%$ CI: 0.69-1.51, $\mathrm{P}=0.93$ ), graft loss (RR: 1.15 , 95\% CI: $0.73-1.80, \mathrm{P}=0.55)$, and patient death (RR: $1.12,95 \% \mathrm{CI}$ : $0.65-2.30, \mathrm{P}=0.54)$. However, basiliximab therapy resulted in a lower incidence of infection (RR: $0.87,95 \% \mathrm{CI}: 0.78-0.97, \mathrm{P}=0.02$ ), and neoplasm (RR: 0.29, 95\% CI: 0.09-0.97, $\mathrm{P}=0.04) .{ }^{42}$

Conversely, a recent study that included de novo high-risk HLAsensitized recipients who had received a kidney from a deceased donor showed different results. A total of 227 patients were randomly assigned to receive either rATG or daclizumab if they met one of the following risk factors; current panel reactive antibodies (PRA) at $>$ $30 \%$, peak PRA of $>50 \%$, loss of a first kidney graft from rejection within two years of transplantation, or loss of two or three previous grafts. Maintenance immunosuppression based on tacrolimus, mycophenolate mofetil, and steroids. Compared with the daclizumab group, patients treated with rATG had a lower incidence of both BPAR ( $15 \%$ vs. $27.2 \% ; \mathrm{P}=0.016)$ and steroid resistant acute rejection $(2.7 \%$ vs. $14.9 \% ; \mathrm{P}=0.002)$ at one year. However, one-year graft and patient survival rates were similar between the two groups. When those who had suffered a graft rejection compared to those who had not, the overall graft survival was significantly higher in the rejection free group $(87.2 \%$ vs. $75 \%$; $\mathrm{P}=0.037)$. The authors concluded that, among high immunological risk renal transplant recipient, rATG was superior to daclizumab in preventing BPAR, but there was no significant benefit to one-year graft or patient survival rates. ${ }^{43}$

\section{Rabbit anti-thymocyte globulin induction versus other depleting agents}

Alemtuzumab, a monoclonal humanised depleting antibody therapy targeting CD52 receptors on both B-cells and T-cells, has been used as off-label for induction therapy and to treat acute rejection posttransplantation. The typical induction dose in renal transplantation has not established yet. When comparing alemtuzumab to rATG as induction therapy in a randomised controlled trial, patient and graft survival rates were similar. ${ }^{44}$ Patients were divided into two groups, high-risk group which conducted receiving induction by either alemtuzumab or rATG induction, while low-risk group to receiving induction by either alemtuzumab or basiliximab. At one-year followup, alemtuzumab group were superior to other groups when compared to rates of BPAR (5\% versus $17 \%, \mathrm{P}$ 0.001). ${ }^{44}$ At 3-year followup, alemtuzumab was significantly superior to basiliximab when concerning the rate of BPAR $(\mathrm{P}=0.003)$. When alemtuzumab was compared to rATG, there was no difference in outcomes $(\mathrm{P}=0.63) .{ }^{44}$ In prospective randomised trial comparing alemtuzumab versus rATG, the immunological risk and maintenance immunosuppression were comparable 'and there was no difference with regards to graft survival alemtuzumab versus rATG (95\% vs. $96 \%) .{ }^{45}$ Acute rejection episodes were significantly higher in the rATG group when compared to the alemtuzumab group $(\mathrm{P}=0.007)$, most of the acute rejection episodes in rATG group occurred in standard criteria donor. At three years, similar outcomes were reported from a larger study of the same group $(n=222)$. The incidence of BPAR episodes in kidney transplant patients was lower in alemtuzumab when compared to rATG $(12 \%$ versus $27 \%, \mathrm{P}=0.03){ }^{44}$ Significant differences in infectious complications observed in both studies. ${ }^{44-46}$

\section{Safety and monitoring}

General tolerability: Rabbit ATG is relatively safe and well tolerated in renal transplantation. Adverse events of rabbit ATG differ in onset and severity, but in general, it is reversible and can be treated. ${ }^{47-50}$ Comparing rabbit ATG with other induction agents, it was comparable to basiliximab concerning incidence of side effects. Also, when compared to daclizumab, no significant difference in side effects. ${ }^{51-53}$

Haematological complications: Haematological abnormalities are common with the use of rabbit ATG due to the non-specific effect on all blood cells. Cross-reacting antibodies against non-lymphoid cells could develop and may lead to thrombosis, thrombocytopenia, neutropenia and haemolytic anaemia. Leukopenia is the most common haematological abnormality and could affect up to $60 \%$ of the patients during the period of induction. ${ }^{54}$

Cytokine release syndrome: It is an acute and immediate complication of rabbit ATG. It characterised by the systemic inflammatory response as activated $\mathrm{T}$ lymphocyte produce a lot of cellular cytokines or tumour necrosis factor- $\alpha$ and interleukin-6. Clinically, it could be manifested by fever, chills, nausea, diarrhoea, vomiting, headache, rashes, tachycardia, dyspnoea and/or pulmonary oedema. Severe manifestation, though rare, could occur as cardio respiratory 
dysfunction or more rarely death. ${ }^{55}$ The incidence of cytokine release syndrome could be decreased by use of premedication as corticosteroids, diphenhydramine and acetaminophen or by slowing the infusion rate. If any serious manifestation occurred, the infusion must stop and immediate use of epinephrine. ${ }^{55}$

Serum sickness: It is delayed-onset, immunologic-mediated reaction directed to rabbit protein present in serum preparation. The onset usually occurs 6-21 days following rabbit ATG administration. Clinically, the patient may develop fever, arthralgia, rashes and lymphadenopathy. Jaw pain is a common manifestation and should increase suspicious in the patient treated with rabbit ATG. The onset of serum sickness could be preceded by pain, erythema, and pruritus at the injection site. Symptoms vary according to the intensity of antigen-antibody reaction. ${ }^{56}$ Serum sickness is a self-limiting disease as it could subside when the antigen removed from circulation. Various treatment options could be used to hasten recovery. The first line of therapy is a high dose of systemic corticosteroid. Antihistamines, analgesics and antipyretics used as adjuvant to steroid. Therapeutic plasma exchange (TPE) could be used as rescue treatment if other measures fail. TPE use could remove serum immune complexes and decrease time to symptoms recovery. ${ }^{56-58}$

Post-transplant diabetes mellitus (PTDM):Post-transplant diabetes mellitus (PTDM) is a well-known complication that may follow renal transplantation. Many factors could contribute to increasing the incidence of PTDM including rabbit ATG induction in a proportion of patients. The rate varies between different groups (1.1-7.3\%) and in part related to maintenance immunosuppression. ${ }^{59-61}$

\section{Infections}

Bacterial infections: It is unclear whether rabbit ATG has impact or not on the incidence of bacterial infection in post-transplant period. Many factors may increase the incidence of bacterial infection as surgical complications, increased immunosuppression, urinary or vascular catheters. Most common reported infections post rabbit ATG induction are bacterial infections. Most common infection post kidney transplantation is urinary tract infections followed by wound infections. ${ }^{62-67}$

\section{Viral infections}

Cytomegalovirus (CMV): Association between rabbit ATG and CMV infection is well established. The incidence and time of infection are dependent on the dose of rabbit ATG at induction period, serology of CMV of donor and recipient before transplantation and CMV prophylaxis status post transplantation. Many prospective randomised controlled trials could not detect any significant increase in the incidence of CMV infection after rabbit ATG induction when compared with other types of induction when adequate CMV prophylaxis was given. On the contrary, the rate of CMV infection was higher with rabbit ATG when compared to basiliximab when CMV prophylaxis not given.68-71

BK virus (BKV): The rate of $\mathrm{BK}$ viremia and $\mathrm{BKV}$ associated nephropathy linked to rabbit ATG induction in renal transplantation. Rabbit ATG induction is an independent risk factor for BKV associated nephropathy. BKV associated nephropathy affects $1-10 \%$ of renal transplant recipients and linked to the strength of the immunosuppression. Higher incidence of BK viremia is related to a higher dose of rabbit ATG.72-75
Fungal infections: In the absence of prophylaxis, invasive fungal infections in renal transplantation were reported with rabbit ATG induction. While the rate of invasive fungal infections are linked to rATG when it is used in the treatment of steroid resistant acute rejections, and the induction with rabbit ATG does not seem to increase the risk fungal infections.52,61,76-77

Malignancy: In general, the risk of malignancy including PTLD is increased post organ transplantation and linked to various mechanisms. However, the studies that reported lower incidence of malignancies including PTLD in patients who had induction therapy with rabbit ATG may be blighted by inadequate sample size, non-standardization of doses maintenance immunosuppression and inadequate follow-up period. $78-85$

\section{Conclusion}

There is no consensus for the optimal agent used as induction immunosuppression in kidney transplantation. rATG use is associated with decreased incidence of delayed graft function and acute rejection episodes. Its use facilitates steroid minimising protocols without compromising long-term graft survival. The safety profile is acceptable and is comparable to other induction regimens using antibodies. There is no standardised protocol for the optimal dose of rATG, and there is wide variability between centres. In order to maximise allograft survival and patient outcomes, it is crucial to tailor the regimen for each patient.

\section{References}

1. Jordan SC, Choi J, Vo A. Kidney transplantation in highly sensitized patients. Br Med Bull. 2015;14(1):113-125.

2. Grenda R. Biologics in renal transplantation. Pediatr Nephrol. 2015;30(7):1087-1098.

3. Bunnapradist S, Takemoto SK. Multivariate analyses of antibody induction therapies. In: Cecka JM \& Terasaki PI (Eds.), Clinical transplants. Los Angeles: UCLA Immunogenetics Center, USA. 2003.

4. Hariharan S, Johnson CP, Bresnahan BA, et al. Improved graft survival after renal transplantation in the United States, 1988 to 1996. $N$ Eng $J$ Med. 2000;342(9):605-612.

5. Aref A, Halawa A, Sharma A. Induction with Thymoglobulin in HighRisk Renal Transplant Patients; Beauty and the Beast. J JNephro Urol. 2016;3(1):028.

6. Sayegh MH, Colvin RB. Case 8-2003: A35-year-old man with early dysfunction of a second renal transplant. $\mathrm{N}$ Engl $\mathrm{J}$ Med. 2003;348:1033-1044.

7. Iwaki Y, Terasaki PI. Sensitization effect. In: Terasaki PI (Ed.) Clinica kidney transplants 1986. Los Angeles: UCLA Tissue Typing Laboratory, USA, 1987;pp. 257.

8. Pelletier RP, Hennessy PK, Adams PW, et al. High incidence of donorreactive delayed-type hypersensitivity in transplant patients. Am J Transplant. 2002;2(10):926-933.

9. Montgomery RA, Zachary AA, Racusen LC, et al. Plasmapheresis and intravenous immune globulin provides effective rescue therapy for refractory humoral rejection and allows kidneys to be successfully transplanted into cross-match-positive recipients. Transplantation. 2000;70(6):887-895.

10. Crespo M, Pascual M, Tolkoff-Rubin N, et al. Acute humoral rejection in renal allograft recipients. I. Incidence, serology and clinical characteristics. Transplantation. 2001;71(5):652-658. 
11. Mauiyyedi S, Crespo M, Collins AB, et al. Acute humoral rejection in kidney transplantation. II. Morphology, immunopathology, and pathologic classification. J Am Soc Nephrol. 2002;13(3):779-787.

12. Bohmig GA, Exner M, Watschinger B, et al. Acute humoral renal allograft rejection. Curr Opin Urol. 2002;12(12):95-99.

13. McKenna RM, Takemoto SK, Terasaki PI. Anti-HLA antibodies after solid organ transplantation. Transplantation. 2000;69(3):319-326.

14. Abe M, Kawai T, Futatsuyama K, et al. Postoperative production of anti-donor antibody and chronic rejection in renal transplantation. Transplantation. 1997;63(11):161-1619.

15. Kerman RH, Susskind B, Kerman DH, et al. Anti-HLA antibodies detected in posttransplant renal allograft recipient sera correlate with chronic rejection. Transplant Proc. 1997;29(1-2):15.

16. Harris PE, Bian H, Reed EF. Induction of high affinity fibroblast growth factor receptor expression and proliferation in human endothelial cells by anti-HLA antibodies: a possible mechanism for transplant atherosclerosis. J Immunol. 1997;159(11):5697-5704.

17. Norman DJ. Clinical immunogenetics. In: Norman DJ \& Turka LA (Eds.), Primer on transplantation. 2nd Ed Mt Laurel: American Society of Transplantation. 2001;pp.51-59.

18. Hardy SLSH, Terasaki PI. Sensitization. In: Cecka JM \& Terasaki PI (Eds.), Clinical transplants 2001. Los Angeles: UCLA Tissue Typing Laboratory, USA. 2001;pp.247.

19. Sanfilippo F, Vaughn WK, Bollinger RR. Comparative effects of pregnancy, transfusion and prior graft rejection on sensitization and renal transplant results. Transplantation. 1982;34:360-366.

20. Niaudet P, Dudley J, Charbit M, et al. Pretransplant blood transfusions with cyclosporine in pediatric renal transplantation. Pediatr Nephrol. 2000;14:451-456.

21. Pelletier RP, Hennessy PK, Adams PW, et al. High incidence of donorreactive delayed-type hypersensitivity in transplant patients. $\mathrm{Am} \mathrm{J}$ Transplant. 2002;2(10):926-933.

22. Jordan SC, Reinsmoen N, Lai $\mathrm{CH}$, et al. Novel immunotherapeutic approaches to improve rates and outcomes of transplantation in sensitized renal allograft recipients. Discov Med. 2012;70(13):235-245.

23. Humar A, Ramcharan T, Denny R, et al. Are wound complications after a kidney transplant more common with modern immunosuppression? Transplantation. 2001;72(12):1920-1923.

24. Meier-Kriesche HU, Arndorfer JA, Kaplan B. Association of antibody induction with short- and long-term cause-specific mortality in renal transplant recipients. J Am Soc Nephrol. 2002;13(3):769-772.

25. Cherikh WS, Kauffman HM, McBride MA, et al. Association of the type of induction immunosuppression with posttransplant lymphoproliferative disorder, graftsurvival, and patient survival after primary kidney transplantation. Transplantation. 2003;76(9):1289-1293.

26. Kidney Disease: Improving Global Outcomes (KDIGO) Transplan Work Group (2009) KDIGO clinical practice guideline for the care of kidney transplant recipients. Am J Transplant. 2003;9Suppl3:S1-S155.

27. Deeks ED, Keating GM. Rabbit anti-thymocyte globulin (thymoglobulin): a review of its use in the prevention and treatment of acute renal allograft rejection. Drugs.2009;69(11):1483-1512.

28. Shapiro R, Jordan ML, Basu A, et al. Kidney transplantation under a tolerogenic regimen of recipient pretreatment and low-dose postoperative immunosuppression with subsequent weaning. Ann Surg. 2003;238(4):520-525.
29. Agha IA, Rueda J, Alvarez A, et al. Short course induction immunosuppression with thymoglobulin for renal transplant recipients. Transplantation. 2002;73(3):473-475.

30. Starzl TE, Murase N, Abu-Elmagd K, et al. Tolerogenic immunosuppression for organ transplantation. Lancet. 2003;361(9368):1502-1510.

31. Gurk-Turner C, Airee R, Philosophe B, et al. Thymoglobulin dose optimization for induction therapy in high risk kidney transplant recipients. Transplantation. 2008;85(10):1425-1430.

32. Goggins WC, Pascual MA, Powelson JA, et al. A prospective, randomized, clinical trial of intraoperative versus postoperative Thymoglobulin in adult cadaveric renal transplant recipients. Transplantation. 2003;76(5):798-802.

33. Agha IA, Rueda J, Alvarez A, et al. Short course induction immunosuppression with thymoglobulin for renal transplant recipients. Transplantation. 2002;73(3):473-475.

34. Gurk-Turner C, Airee R, Philosophe B, et al. Thymoglobulin dose optimization for induction therapy in high risk kidney transplant recipients. Transplantation. 2008;85(10):1425-1430.

35. Peddi VR, Bryant M, Roy-Chaudhury P, et al. Safety, efficacy, and cost analysis of thymoglobulin induction therapy with intermittent dosing based on $\mathrm{CD} 3+$ lymphocyte counts in kidney and kidney- pancreas transplant recipients. Transplantation. 2002;73(9):1514-1518.

36. Stevens RB, Mercer DF, Grant WJ, et al. Randomized trial of single- dose versus divided-dose rabbit anti-thymocyte globulin induction in renal transplantation: an interim report. Transplantation. 2008;85(10):1391-1399.

37. Wong W, Agrawal N, Pascual M, et al. Comparison of two dosages of thymoglobulin used as a short-course for induction in kidney transplantation. Transplant Int. 2006;19(8):629-635.

38. Peddi VR, Bryant M, Roy-Chaudhury P, et al. Safety, efficacy, and cost analysis of thymoglobulin induction therapy with intermittent dosing based on $\mathrm{CD} 3+$ lymphocyte counts in kidney and kidney-pancreas transplant recipients. Transplantation. 2002;73(9):1514-1518.

39. Stratta RJ, Sundberg AK, Farney AC, et al. Experience with alternateday Thymoglobulin induction in pancreas transplantation with portalenteric drainage. Transplant Proc. 2005;37(8):3546-3548.

40. Charpentier B, Rostaing L, Berthoux F, et al. A three-arm study comparing immediate tacrolimus therapy with anti-thymocyte globulin induction therapy followed by tacrolimus or cyclosporine $\mathrm{A}$ in adult renal transplant recipients. Transplantation. 2003;75(6):844-851.

41. Mourad G, Gar rigue V, Squifflet JP, et al. Induction versus noninduction in renal transplant recipients with tacrolimus-based immunosuppression. Transplantation. 2001;72(6):1050-1055.

42. Liu Y, Zhou P, Han M, et al. Basiliximab or anti thymocyte globulin for induction therapy in kidney transplantation: a meta-analysis. Transplant Proc. 2010;42(5):1667-1670.

43. Noel C, Abramowicz D, Durand D, et al. Daclizumab versus antithymocyte globulin in high-immunological-risk renal transplant recipients. J Am Soc Nephrol. 2009;20(6):1385-1392.

44. Hanaway MJ, Woodle ES, Mulgaonkar S, et al. Alemtuzumab induction in renal transplantation. N Engl J Med. 2011;364(20):1909-1919.

45. Farney A, Sundberg A, Moore P, et al. A randomized trial of alemtuzumab versus anti-thymocyte globulin induction in renal and pancreas transplantation. Clin Transplant. 2008;22(1):41-49. 
46. Far ney AC, Doares W, Rogers J, et al. A randomized trial of alemtuzumab versus antithymocyte globulin induction in renal and pancreas transplantation. Transplantation. 2009;88(6):810-819.

47. Boothpur R, Hardinger KL, Skelton RM, et al. Serum sickness after treatment with rabbit anti-thymocyte globulin in kidney transplant recipients with previous rabbit exposure. Am J Kidney Dis. 2010;55(1):141-143.

48. Kandil E, Alabbas H, Distant D. Anaphylaxis to thymoglobulin: a case report and literature review. J La State MedSoc. 2009;161(5): 279-281.

49. Pham PT, Pham PM, Miller JM, et al. Polyclonal antibody-induced serum sickness presenting as rapidly progressive descending paralysis. Transplantation. 2007;83(12):1657.

50. Tanriover B, Chuang P, Fishbach B. Polyclonal antibody-induced serum sickness in renal transplant recipients: treatment with therapeutic plasma exchange. Transplantation. 2005;80(2):279-281.

51. Lebranchu Y, Bridoux F, Büchler M, et al. Immunoprophylaxis with basiliximab compared with antithymocyte globulin in renal transplan patients receiving MMFcontaining triple therapy. Am J Transplant. 2002;2(1):48-56.

52. Brennan DC, Daller JA, Lake KD, et al. Rabbit antithymocyte globulin versus basiliximab in renal transplantation. N Engl J Med. 2006;355(19):1967-1977.

53. Abou-Ayache R, Büchler M, Lepogamp P, et al. CMV infections after two doses of daclizumab versus thymoglobulin in renal transplant patients receiving mycophenolate mofetil, steroids and delayed cyclosporine A. Nephrol Dial Transplant. 2008;23(6):2024-2032.

54. Bowman LG, Edwards A, Brennan BC. The role of rabbit antithymocyte globulin in renal transplantation. Expert Opinion on Orphan Drugs. 2014;2(9):971-987.

55. Guttmann RD, Caudrelier P, Alberici G, et al. Pharmacokinetics, foreign protein immune response, cytokine release, and lymphocyte subsets in patients receiving thymoglobulin and immunosuppression. Transplant Proc. 1997;29(7A):24S-26S.

56. Boothpur R, Hardinger KL, Skelton RM, et al. Serum sickness after treatment with rabbit antithymocyte globulin in kidney transplant recipients with previous rabbit exposure. Am $J$ Kidney Dis. 2010;55(1):141-143.

57. Tanriover B, Chuang P, Fishbach B. Polyclonal antibody-induced serum sickness in renal transplant recipients: treatment with therapeutic plasma exchange. Transplantation. 2005;80:279-278.

58. Conti DJ, Elbahloul O, Gallichio MH. Coagulopathy associated with thymoglobulin induction therapy following renal transplantation [abstract no. 1299]. Am J Transplantation. 2008;8(Suppl 2):524.

59. Charpentier B, Rostaing L, Berthoux F, et al. A three-arm study comparing immediate tacrolimus therapy with antithymocyte globulin induction therapy followed by tacrolimus or cyclosporine $\mathrm{A}$ in adult renal transplant recipients. Transplantation. 2003;75(6):844-851.

60. Mourad G, Garrigue V, Squifflet J-P, et al. Induction versus noninduction in renal transplant recipients with tacrolimusbased immunosuppression. Transplantation. 2001;72:1050-1055.

61. Lebranchu Y, Bridoux F, Büchler M, et al. Immunoprophylaxis with basiliximab compared with antithymocyte globulin in renal transplant patients receiving MMFcontaining triple therapy. Am J Transplant. 2002;2(1):48-56.

62. Alangaden GJ, Thyagarajan R, Gruber SA, et al. Infectious complications after kidney transplantation: current epidemiology and associated risk factors. Clin Transplant. 2006;20(4):401-409.
63. Schwartz JJ, Ishitani MB, Weckwerth J, et al. Decreased incidence of acute rejection in adolescent kidney transplant recipients using antithymocyte induction and triple immunosuppression. Transplantation. 2007;84(6):715-721.

64. Abou-Jaoude MM, Ghantous I, Najm R, et al. Daclizumab versus antithymocyte globulin-fresenius as induction therapy for low-risk kidney transplant recipients. Transplant Proc. 2003;35(7):2731-2732.

65. Brennan DC, Daller JA, Lake KD, et al. Rabbit antithymocyte globulin versus basiliximab in renal transplantation. $N$ Engl J Med. 2006;355:1967-1977.

66. Carlsen J, Johansen M, Boesgaard S. Induction therapy after cardiac transplantation: a comparison of anti-thymocyte globulin and daclizumab in the prevention of acute rejection. $J$ Heart Lung Transplant. 2005;24:296-302.

67. Mariat C, Afiani A, Alamartine E, et al. A pilot study comparing basiliximab and anti-thymocyte globulin as induction therapy in sensitized renal allograft recipients. Transplant Proc. 2001;33:3192-3193.

68. Jamil B, Nicholls KM, Becker GJ, et al. Influence of anti-rejection therapy on the timing of cytomegalovirus disease and other infections in renal transplant recipients. Clin Transplant. 2000;14:14-18.

69. Zamora MR. Controversies in lung transplantation: managemen of cytomegalovirus infections. $J$ Heart Lung Transplant. 2002;21(8):841-849.

70. Huurman VA, KalpoeJS, van de Linde P. Choice of antibody immunotherapy influences cytomegalovirus viremia in simultaneous pancreas-kidney transplant recipients. Diabetes Care. 2006;29:842-847.

71. Ozaki KS, Pestana JO, Granato CF, et al. Sequential cytomegalovirus antigenemia monitoring in kidney transplant patients treated with antilymphocyte antibodies. Transpl Infect Dis. 2004;6:63-68.

72. Hirsch HH, Brennan DC, Drachenberg CB, et al. Polyomavirus-associated nephropathy in renal transplantation: interdisciplinary analyses and recommendations. Transplantation. 2005;79(10):1277-1286.

73. Dadhania D, Snopkowski C, Ding R, et al. Epidemiology of BK virus in renal allograft recipients: independent risk factors for $\mathrm{BK}$ virus replication. Transplantation. 2008;86(4):521-528.

74. Smith JM, Dharnidharka VR, Talley L, et al. BK virus nephropathy in pediatric renal transplant recipients: an analysis of the North American Pediatric Renal Trials and Collaborative Studies (NAPRTCS) registry. Clin J Am SocNephrol. 2007;2:1037-1042.

75. Hirsch HH, Knowles W, Dickenmann M, et al. Prospective study of polyomavirus type BK replication and nephropathy in renal-transplant recipients. N Engl J Med. 2002;347(7):488-496.

76. Wheat LJ, Connolly P, Durkin M, et al. False-positive Histoplasma antigenemia caused by antithymocyte globulin antibodies. Transpl Infect Dis. 2004;6(1):23-27.

77. Wheat LJ, Connolly P, Durkin M, et al. Elimination of false-positive Histoplasma antigenemia caused by human anti-rabbit antibodies in the second-generation Histoplasma antigen assay. Transpl Infect Dis. 2006;8:219-221.

78. Dharnidharka VR, Stevens G. Risk for post-transplant lymphoproliferative disorder after polyclonal antibody induction in kidney transplantation. Pediatr Transplant. 2005;9(5):622-626.

79. Caillard S, Dharnidharka V, Agodoa L, et al. Posttransplant lymphoproliferative disorders after renal transplantationin the United States in era of modern immunosuppression. Transplantation. 2005;809:1233-1243 
80. Bustami RT, Ojo AO, Wolfe RA, et al. Immunosuppressionand the risk of post-transplant malignancy among cadaveric first kidney transplant recipients. Am J Transplant. 2004;4(1):87-93.

81. Arichi N, Kishikawa H, Nishimura K, et al. Malignancy following kidney transplantation. Transplant Proc. 2008;40(7):2400-2402.

82. Cherikh WS, Kauffman HM, McBride MA, et al. Association of the type of induction immunosuppression with posttransplant lymphoproliferative disorder, graft survival, and patient survival after primary kidney transplantation. Transplantation. 2003;76(9):1289-1293.
83. Bustami RT, Ojo AO, Wolfe RA, et al. Immunosuppression and the risk of post-transplant malignancy among cadaveric first kidney transplant recipients. Am J Transplant. 2004;4(1):87-93.

84. KirkAD, Cherikh WS, Ring M, et al. Dissociation of depletional induction and posttransplant lymphoproliferative diseasein kidney recipients treated with alemtuzumab. Am J Transplant. 2007;7(11):2619-2625.

85. Weimert NA, Alloway RR. Renal Transplantation in High-Risk Patients. Drugs. 2007;67(11):1603-1627. 